\title{
Letter: A call for a radical change in research evaluation in Spain
}

\author{
Emilio Delgado-López-Cózar; Ismael Ràfols; Ernest Abadal
}

Nota: Esta carta se puede leer en español en:

http://www.profesionaldelainformacion.com/contenidos/2021/may/delgado-rafols-abadal_es.pdf

Cómo citar este artículo:

Delgado-López-Cózar, Emilio; Ràfols, Ismael; Abadal, Ernest (2021). "Letter: A call for a radical change in research evaluation in Spain". Profesional de la información, v. 30, n. 3, e300309.

https://doi.org/10.3145/epi.2021.may.09

Manuscript received on $19^{\text {th }}$ May 2021

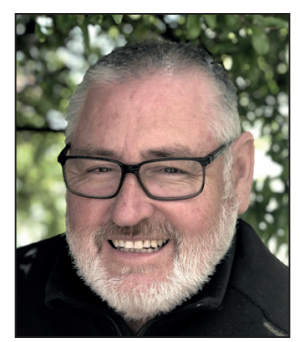

\author{
Emilio Delgado-López-Cózar \\ https://orcid.org/0000-0002-8184-551X \\ Universidad de Granada \\ Fac. de Comunicación y Documentación \\ Campus Cartuja \\ 18071 Granada, Spain \\ edelgado@ugr.es
}

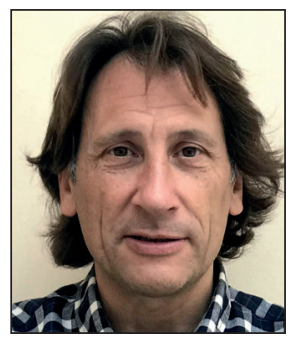

\section{Ismael Ràfols}

https://orcid.org/0000-0002-6527-7778

Leiden University, Centre for Science and Technology Studies (CWTS), Leiden, The Netherlands

University of Sussex, Science Policy Research Unit (SPRU), Brighton, United Kingdom

i.rafols@cwts.leidenuniv.nI

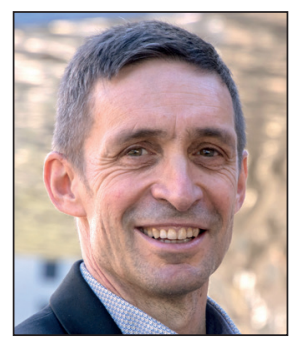

\author{
Ernest Abadal \\ https://orcid.org/0000-0002-9151-6437 \\ Universitat de Barcelona \\ Fac. d'Informació i Mitjans Audiovisuals \\ Centre de Recerca en Informació, \\ Comunicació i Cultura \\ Melcior de Palau, 140 \\ 08014 Barcelona, Spain \\ abadal@ub.edu
}

\begin{abstract}
This letter is a call to the Spanish scientific authorities to abandon current research evaluation policies, which are based on an excessive and indiscriminate use of bibliometric indicators for nearly all areas of scientific activity. This narrow evaluation focus is especially applied to assess the individual performance of researchers. To this end, we first describe the contexts in which the journal impact factor (JIF) and other bibliometric indicators are being used. We then consider the toxic effects of this abuse of indicators. Finally, we outline some significant transformations and initiatives being introduced in various academic fields and regions of the world. These international initiatives offer alternatives to bibliometrics that can improve evaluation processes, and we urge political leaders in Spain to adopt and develop them.
\end{abstract}

\section{Keywords}

Research evaluation; Performance assessment of researchers; Research policy; Bibliometric indicators; San Francisco Declaration on Research and Assessment; DORA, Leiden Manifesto; Journal Impact Factor; Journal level metrics; Citation counts; Scientific journals; Scholarly publishing; Scientific ethics.

\section{Spain: the kingdom of the impact factor}

In Spain today, it is impossible to enter, advance, or succeed in any field of scientific research without publishing a substantial number of articles in journals with a high impact factor in the Journal Citation Reports (JCR) or other rankings of a similar nature, such as the SCImago Journal Rank (SJR) or Spanish Foundation for Science and Technology (Fecyt) journal ranking. No academic field is immune to the domination of the impact factor, which is the standard for scientific evaluation in the country.

A letter bearing the eloquent title "Publish, publish... cursed!," written by a Spanish professor with an extensive academic career, was published recently (Fernández-Cano, 2021). Without explicitly mentioning Spain, this letter offers a very accurate picture of the context of scientific activity in this country. The use of indicators based on journal-level metrics has expanded to affect: 
- All fields of knowledge, from experimental research, technology, and social sciences to the arts and humanities.

- All the institutions that participate in the country's scientific network, including funding agencies, evaluation and accreditation agencies, universities, public research and innovation institutions, hospitals, and other public and private organizations involved in the production of scientific knowledge.

- Every activity of academic life: applications for scholarships and grants, projects, programs, recruitment and promotion of professors and researchers, evaluation of teaching programs (masters and doctoral programs), and awards.

- All organizational levels involved in research, whether individuals (professors, researchers, and professionals) or groups (research groups and departments).

In short, every aspect of a researcher's day-to-day activity, from the beginning of their career through to retirement, is shaped by the requirement to publish papers in JCR or similar journals:

- Undergraduate or master's students who have received a research initiation grant will be rewarded with a bonus if their studies result in the publication of a paper in a JCR journal. https://www.uma.es/media/files/I_PPIT-OTRI-DIV-10_A1.pdf

- In many Spanish doctoral programs, PhD students are not allowed to defend their thesis until they have published a paper, usually in the form of an article in an indexed journal. When a thesis is presented as a collection of published works, it must include at least three articles published in JCR journals (sciences), which also have to be high-ranking publications (top quartiles).

https://escueladoctoral.uca.es/doctorado/normativa-para-la-presentacion-y-lectura-de-tesis

- To receive a Spanish government scholarship for doctoral studies (known as FPU or FPI), applicants must be endorsed by a mentor or a research team with a significant number of publications. https://www.pap.hacienda.gob.es/bdnstrans/GE/es/convocatoria/733672/document/473444

- For PhD graduates seeking postdoctoral fellowships (such as the Juan de la Cierva or Ramón y Cajal fellowships), the number of papers published by them, their mentor, and the research team endorsing them is extremely important. https://www.boe.es/eli/es/o/2019/06/20/cnu692

- To secure a faculty position at a university or a job at a research center, applicants must have articles published in journals with high JCR impact factors whatever the field of knowledge, and in journals with good SJR scores in the case of the humanities.

https://www.ugr.es/sites/default/files/2018-09/ACG1343.pdf

- University professors seeking accreditation from the National Agency for Quality Assessment and Accreditation (Ane$\mathrm{ca}$ ) or promotion to the different professional categories in the university hierarchy (entry- or upper-level assistant professor, associate professor, and full professor) are required to have published a minimum number of articles in journals ranked in $J C R$ or similar (SJR for the humanities), a proportion of which must be in the first or second quartile. The number of publications required ranges from 20 to 150 (Delgado-López-Cózar; Martín-Martín, 2019). http://www.aneca.es/Programas-de-evaluacion/Evaluacion-de-profesorado/ACADEMIA/Criterios-Diciembre-2019

- To receive the six-year research productivity bonus (known in Spain as the sexenio) from the National Commission for the Evaluation of Research Activity (Cneai), university professors and researchers working under the Spanish National Research Council must have had a minimum of five articles published in journals ranked in specific JCR or SJR quartiles within a six-year period. There are very precise methods for rating each journal (9-10 points for JCR Q1 journals, with scores descending therefrom) (Delgado-López-Cózar, 2021). These sexenios are of vital importance, as only professors who have them can endorse scholarship applicants, act as thesis advisors, teach in official masters and PhD programs, work on evaluation committees (for theses and faculty positions), direct research and innovation projects, and receive productivity bonuses offered by universities or regional governments (Aneca, 2009). Since 2012, they have even been used to determine teaching loads, which are reduced for professors with active sexenios but increased for faculty members without them.

https://www.boe.es/diario_boe/txt.php?id=BOE-A-2012-5337

- Researchers who want to secure research projects financed by national, regional, or local funds need a significant number of publications in prestigious journals on their CVs. The publishing history of the research team is a key factor in the approval of these projects.

- Research centers seeking official recognition as centers of excellence (under the Severo Ochoa or María de Maeztu accreditation programs), entitling them to receive the most generous funding available in Spain, have to meet the prerequisite of having $75 \%$ of their publications published in first-quartile journals. Since this is based on the share, this actively discourages publication in local journals and languages.

https://bit.ly/2SbgxGg

This insistence on using journal-level metrics to evaluate everything, everyone, and everywhere at all times is exacerbated by the repercussions of university rankings on the governance and strategic approaches of universities and research centers, especially the Shanghai Ranking ( $A R W U$ ), QS, THE, and Leiden Ranking. Because the position of institutions in these rankings depends on the number of articles they publish in high-impact journals according to Web of Science or 
Scopus, the directors of these institutions offer all kinds of incentives, programs, and initiatives aimed at increasing that number. There is a clear conviction that university rankings are not only powerful marketing tools but also certifications of the quality of the institution.

This is the logical corollary of a scientific evaluation policy established in the 1990s and maintained over the past three decades. Few public research policies have been maintained for so long in the same direction. Hence, the toxic effects of this policy have now become deep and entrenched.

\section{Toxic effects}

This reductionist vision of evaluation is having harmful consequences at both the individual and collective level. Some of these consequences are outlined below (Welpe et al., 2015):

A. The promotion of a "publish or perish" culture: publication becomes the ultimate objective and essential purpose of all research activity. Scientific activity is thus transformed into an obsessive game, aimed entirely at accumulating more publications and increasing the number of citations. This is publishing for publishing's sake, even if the papers are empty, futile, or repetitive, offering no significant knowledge, innovation, or social benefit (Rodríguez-Navarro, 2009; Delgado-López-Cózar; Martín-Martín, 2019; Fernández-Cano, 2021).

B. Academic activity has also been impoverished by this phenomenon. The balance of the three missions of the university (teaching, research, and social contributions of research) has been disrupted by the effects of the JIF. There is ample evidence today that teaching activities have become relatively neglected by a fraction of lecturers, as a consequence of recruitment and promotion systems that are exclusively focus on rewarding scientific publications in high-JIF journals, under the assumption that publications constitute a good proxy for research. Researchers thus view publication as their most important work, abandoning or reducing efforts towards "unproductive" activities that do not further their careers, such as teaching, public engagement and dissemination, or transfer (De-Rijcke et al., 2016; Feenstra; Delgado-López-Cózar, 2021). This is a problem that especially affects young researchers (Rodríguez-Bravo; Nicholas, 2019).

C. Lines of research have also been altered (López; Hicks, 2015) because there are clearly certain subjects that are more likely to be accepted for publication than others that may actually have a greater positive impact on society (societal benefits and/or social impact) but are not especially attractive to journal publishers. This shift in research agendas involves the replacement of lines of research that are slow in yielding results, uncertain, complex, or costly with subjects that are in vogue, easier to study, or produce clear and immediate results (De-Rijcke et al., 2016; Feenstra; Delgado-López-Cózar, 2021). Fear of failure prevents researchers from taking risks or being creative, which are essential for cutting-edge science.

D. The desire to publish at any price also fosters the proliferation of unethical behavior, such as authorship of articles in which some listed authors may not have participated sufficiently, unscrupulous publishing practices (plagiarism, self-plagiarism, duplicate publication, citation manipulation, etc.) (Martin, 2013; Feenstra; Delgado-López-Cózar; Pallarés, 2021), or outright fraud (fabrication of results, etc.).

E. Finally, the international scientific journals market has also changed dramatically. The JIF has a "reputation effect" on journals that creates a publishing imbalance skewed towards indexed journals in the first and second quartiles (Q1 and Q2). These quartiles represent only $50 \%$ of all titles, but they publish more than $70 \%$ of all articles (De-Moya-Anegón, 2020). However, even more troubling is the fact that this pressure on authors to publish in high-impact journals has pushed up article processing charges (APCs), with no mechanism in place to curb their upward trajectory because the demand for publishing space allows the prices to keep rising. For example, Nature has set its price for publishing an article in open access at 9,500€.

https://www.sciencemag.org/news/2020/11/9500-nature-journals-will-now-make-your-paper-free-read

Open-access journals with APCs, or hybrid models, are also logically located in the first quartiles. This is only the tip of the iceberg of a widespread increase in the fees demanded of authors to publish in many scientific journals.

\section{International evaluation reforms}

The situation of research evaluation in Spain, with its uncontested focus on impact factors, contrasts with the ongoing reforms being developed in other countries. In this section, we outline some of the significant initiatives and transformations that are being introduced in various regions of the world.

In 2013, the San Francisco Declaration on Research and Assessment (DORA) became the first major movement against the use of the JIF, with its call for the elimination of the use of journal-based metrics in assessments for project funding and hiring or promotion decisions. Initially promoted by publishers in the field of biology, over the past eight years DORA has received support from more than 17,000 researchers and close to 2,200 organizations in 145 countries. Since the declaration, DORA has evolved into an organization dedicated to promoting best practices in assessment, with the support of important institutions such as the Howard Hughes Medical Institute, Swiss National Science Foundation, Research Council of Norway, and Wellcome Trust.

https://sfdora.org 
In 2015, the Leiden Manifesto (Hicks et al., 2015) was published, setting out ten principles for the appropriate use of quantitative indicators in research evaluation. The manifesto places the focus on the contextualized use of indicators for evaluation. Evaluation should be conducted against the stated objectives of the research and taking into account the geographical region and discipline. Special attention is given to the uncertainties of indicators at low levels of aggregation, for example, for individuals. Also published in 2015 was The Metric Tide (Wilsdon et al., 2015), a report for the UK government that developed the idea of "responsible metrics," i.e., a fair use of indicators based on the different quality characteristics and contributions of research, not just on bibliometric visibility.

Following these initiatives, prestigious scientific institutions have supported a shift in evaluation to promote the appropriate use of indicators, with special emphasis on avoiding the evaluative use of the impact factor as a proxy for scientific quality; For example, in 2016, the Forum for Responsible Research Metrics was created in the UK with the aim of advising British universities on the use of indicators in evaluation.

https://www.universitiesuk.ac.uk/policy-and-analysis/research-policy/open-science/Pages/forum-for-responsibleresearch-metrics.aspx

The forum includes experts from the British funding agency UK Research and Innovation (UKRI) and from major universities. Another example is the Evaluation Working Group, created in 2018 by the International Network of Research Management Societies (Inorms).

https://inorms.net/research-evaluation-group

Open science initiatives have also constituted a step forward in the adoption of reforms. Since the most prestigious journals (with the highest JIFs) are not open access, scientific managers have realized that open science would be slow to spread unless the approach to evaluation changed (Wilsdon et al., 2017). For example, in 2018 the European University Association (EUA) published a report supporting the development of flexible, transparent, fair, and robust approaches to assessment that would promote open science.

https://eua.eu/downloads/publications/eua-roadmap-on-research-assessment-in-the-transition-to-open-science.pdf

In recent years, there has been a flurry of institutional initiatives proposing new evaluation models that balance quantitative and qualitative information and place the value of the contribution of the research, i.e., the contents of the article, above the value of the journal. Some of these initiatives are outlined on the DORA website (see the blog, resources page, and case studies). Worthy of special mention for their potential impact in their respective regions are the following initiatives:

- Several European funding agencies, including research foundations in the Netherlands, Ireland, Switzerland, and the UK, have reviewed the impact of evaluation on careers, and are adopting the use of narrative CV formats.

- In 2019, the Latin American Council of Social Sciences (Clacso) created the Latin American Forum on Scientific Evaluation (Folec), with the support of most national councils in the region, to move towards an approach to evaluation that would support open science, with democratizing models that are committed to solving societal problems. https://www.clacso.org/folec

- In 2020, China's science policy abandoned its focus on bibliometrics (very much centered on Web of Science), opening up to models that incorporate more databases, peer review evaluation, and the assessment of local relevance (Zhang; Sivertsen, 2020).

All these movements suggest that the evaluation of research has entered a new era, moving towards more pluralistic models that take into account various factors of the research (scientific impact but also social and local impact; prestige but also accessibility, etc.) in the evaluation process.

\section{A call for action to science policymakers: it is high time to sign and comply with DORA and Leiden}

In light of the toxic effects of evaluation based on impact factors, and in view of the reforms and transformations being implemented around the world, we call upon the scientific authorities of Spain, especially in the national and regional science and research ministries and the rectors of universities and directors of research centers, to sign and comply with the DORA declaration and to follow the recommendations for the use of bibliometric indicators set forth in the Leiden Manifesto. A first step in this direction has already been taken by funding agencies in Catalonia ( $A Q U$ and Icrea) and the Basque Country (Ikerbasque), and some universities (such as the Universitat Oberta de Catalunya, UOC) by signing DORA. Very recently (20 April 2021), the Spanish Research Agency (Agencia Española de Investigación, AEI) also announced that it will sign DORA.

https://cutt.ly/Ub8b4L2

The institutions that sign these declarations should not only sign, but genuinely adhere to, fulfil, and implement their postulates. Since it would be unacceptable for signatories of DORA to continue using impact factors as their main evaluation criteria, we expect Spanish signatories to swiftly engage in reforming their evaluation practices. These agencies have taken the first step. Now, policy action must follow to confirm that such new evaluation models are in fact applied and that signing is not merely a cosmetic act. 
We hope that more institutions will join initiatives for reforming evaluation and that this letter may make some small contribution to supporting such change. We believe that this public call may also be relevant in other countries that still use evaluation models similar to that applied in Spain.

\section{References}

Aneca (2009). Informe sobre el estado de la evaluación externa de la calidad en las universidades españolas. Madrid: Aneca. http://deva.aac.es/include/files/deva/informes/evaluacion_externa/Informe_Calidad_2009.pdf

Delgado-López-Cózar, Emilio (2021). Sexenios 2020: Una revisión de estilo y un insólito a la par que loable esfuerzo de transparencia en el reino de los índices de impacto.

https://doi.org/10.13140/RG.2.2.14771.14885

Delgado-López-Cózar, Emilio; Martín-Martín, Alberto (2019). “El factor de impacto de las revistas científicas sigue siendo ese número que devora la ciencia española: ¿hasta cuándo?". Anuario ThinkEPI, v. 13.

https://doi.org/10.3145/thinkepi.2019.e13e09

De-Moya-Anegón, Félix (2020). Frecuencia de publicación e impacto de la producción científica mundial. Scimago Lab. https://www.scimagolab.com/blog/2020/frecuencia-de-publicacion-e-impacto-de-la-produccion-cientifica-mundial

De-Rijcke, Sarah; Wouters, Paul F.; Rushforth, Alex D.; Franssen, Thomas P.; Hammarfelt, Björn (2016). "Evaluation practices and effects of indicator use: a literature review". Research evaluation, v. 25, n. 2, pp. 161-169.

https://doi.org/10.1093/reseval/rvv038

Feenstra, Ramón A.; Delgado-López-Cózar, Emilio (2021). The footprint of a metrics-based research evaluation system on Spanish philosophical scholarship: an analysis of researchers perceptions.

https://arxiv.org/abs/2103.11987

Feenstra, Ramón A.; Delgado-López-Cózar, Emilio; Pallarés-Domínguez, Daniel (2021). “Research misconduct in the fields of ethics and philosophy: researchers' perceptions in Spain". Science and engineering ethics, v. 27, n. 1, pp. 1-21. https://doi.org/10.1007/s11948-021-00278-w

Fernández-Cano, Antonio (2021). “Publish, publish... cursed!”. Scientometrics, v. 126, n. 4, pp. 3673-3682.

https://doi.org/10.1007/s11192-020-03833-7

Hicks, Diana; Wouters, Paul; Waltman, Ludo; De-Rijcke, Sarah; Ràfols, Ismael (2015). “Bibliometrics: the Leiden Manifesto for research metrics". Nature, v. 520, n. 7548, pp. 429-431.

https://doi.org/10.1038/520429a

López-Piñeiro, Carla; Hicks, Diana (2015). “Reception of Spanish sociology by domestic and foreign audiences differs and has consequences for evaluation". Research evaluation, v. 24, n. 1, pp. 78-89.

https://doi.org/10.1093/reseval/rvu030

Martin, Ben R. (2013). "Whither research integrity? Plagiarism, self-plagiarism and coercive citation in an age of research assessment". Research policy, v. 42, n. 5, pp. 1005-1014.

https://doi.org/10.1016/j.respol.2013.03.011

Rodríguez-Bravo, Blanca; Nicholas, David (2019). "Reputación y comunicación científica: investigadores españoles en el inicio de su carrera". Profesional de la información, v. 28, n. 2, e280203.

https://doi.org//10.3145/epi.2019.mar.03

Rodríguez-Navarro, Alonso (2009). "Sound research, unimportant discoveries: research, universities, and formal evaluation of research in Spain". Journal of the American Society for Information Science and Technology, v. 60, n. 9, pp. 1845-1858.

https://doi.org/10.1002/asi.21104

Welpe, Isabell M.; Wollersheim, Jutta; Ringelhan, Stefanie; Osterloh, Margit (eds.) (2015). Incentives and performance. Heidelberg: Springer. ISBN: 9783319097855

Wilsdon, James; Allen, Liz; Belfiore, Eleonora; Campbell, Philip; Curry, Stephen; Hill, Steven; Jones, Richard; Kain, Roger; Kerridge, Simon R.; Thelwall, Mike; Tinkler, Jane; Viney, Ian; Wouters, Paul (2016). The metric tide: Independent review of the role of metrics in research assessment and management.

https://doi.org/10.13140/RG.2.1.4929.1363

Wilsdon, James; Bar-Ilan, Judit; Frodeman, Robert; Lex, Elisabeth; Peters, Isabella; Wouters, Paul (2017). Next-generation metrics: Responsible metrics and evaluation for open science. Report of the European Commission Expert Group on Altmetrics. Brussels: European Commission.

https://op.europa.eu/en/publication-detail/-/publication/b858d952-0a19-11e7-8a35-01aa75ed71a1

Zhang, Lin; Sivertsen, Gunnar (2020). "The new research assessment reform in China and its implementation". Scholarly assessment reports, v. 2, n. 1.

https://www.scholarlyassessmentreports.org/articles/10.29024/sar.15 